\title{
Countermeasure Method for Stope Instability in Crown Pillar Area of Cut and Fill Underground Mine
}

\author{
Tri Karian1,2, Hideki Shimada1, Takashi Sasaoka1, Sugeng Wahyudi', \\ Deyu Qian', Budi Sulistianto \\ ${ }^{1}$ Department of Earth Resources Engineering, Kyushu University, Fukuoka, Japan \\ ${ }^{2}$ Department of Mining Engineering, Institut Teknologi Bandung, Bandung, Indonesia \\ Email: tri13r@mine.kyushu-u.ac.jp, shimada@mine.kyushu-u.ac.jp, sasaoka@mine.kyushu-u.ac.jp, \\ wahyudi_sugeng@mine.kyushu-u.ac.jp, deyu12r@mine.kyushu-u.ac.jp, bst@mining.itb.ac.id
}

Received 15 February 2016; accepted 14 March 2016; published 17 March 2016

Copyright (C) 2016 by authors and Scientific Research Publishing Inc.

This work is licensed under the Creative Commons Attribution International License (CC BY). http://creativecommons.org/licenses/by/4.0/

(c) (i) Open Access

\begin{abstract}
Maintaining stability as well as optimizing recovery of crown pillar, a pillar separating surface area with the uppermost stope in overhand cut and fill underground mining method, is important. Failures in stope may lead to crown pillar failures and cause surface subsidence. Increasing crown pillar thickness will increase crown pillar stability yet reduce mining recovery because part of crown pillar is formed by ore body. Preventing stope failure is the key to maintain stability and optimize recovery of crown pillar. Therefore, it is important to study countermeasure method for stope failure especially in crown pillar area. An attempt has been made to investigate the effectiveness of various countermeasures for stope failure in crown pillar area by means of parametric study. The result shows active type support system is effective for supporting stope in high vertical stress condition while the passive one needs to be installed if the stope is opened in high horizontal stress condition. In general, more supporting capacity from both type support systems is needed if the stope is opened in more severe geological condition. Another countermeasures, sill pillar and surface pile, are introduced for stope instability in crown pillar and non-crown pillar area. Sill pillar is an abandoned slice of unstable stope based on stability analysis. Sill pillar is very effective to stabilize stope both in crown pillar and non-crown pillar area, especially for stope in high horizontal stress condition. Sill pillar application in model with stress ratio 2 can optimize 20 meter thickness of crown pillar into 5 meter. Another proposed countermeasure is surface pile. Surface pile can be installed from the surface to improve stability of crown pillar and stope. The most effective use of surface pile is found in simulation of model with stress ratio 0.75 where surface pile can optimize 15 meter thickness of crown pillar into 5 meter.
\end{abstract}




\section{Keywords}

\section{Crown Pillar, Stope Stability, Active and Passive Type Support System, Sill Pillar, Surface Pile}

\section{Introduction}

Minimizing environmental impact at surface area is one of the reasons to apply underground mining method for natural resources development. Nowadays, the application of surface mining is preferable to underground mining because of several reasons, varying from economic to safety issues. However, when the environmental and social constraint arise, it might be applied as the solution to maximize benefit of natural resources development while keep maintaining those constraints. Furthermore, its environmental impacts are relatively low compared to the one of the surface mining since its mining operation is conducted beneath the surface. Therefore, underground mining can be an answer to extract constrained valuable natural resources.

One of the underground mining methods which suitable for the condition above is overhand cut and fill. In this method, ore deposit is mined in a horizontal slice (Figure 1). A mined out slice is then backfilled by using the backfilling material to provide additional support for the country rock surrounding the stope as well as the base to execute upper slice. Consequently, stope stability is improved for a long time even after the mine is abandoned. As a consequence of using the backfilling material, it has a relatively high cost [1] compare to the other underground mining method and only suitable for a high value deposit such as gold and silver vein deposit.

Even though the overhand cut and fill mining method has environmental protection advantages, the possibility to disturb the surface still exist. Several surface subsidence cases due to application of this method have occurred in the past [2]. It may occur as a result of underground opening failure, for example the stope failure. When stope failure is happened, there is a possibility that it will continue until the rock mass separates uppermost stope with the surface, which named crown pillar. This will lead to surface subsidence especially when stope is located near surface area or crown pillar thickness is slender.

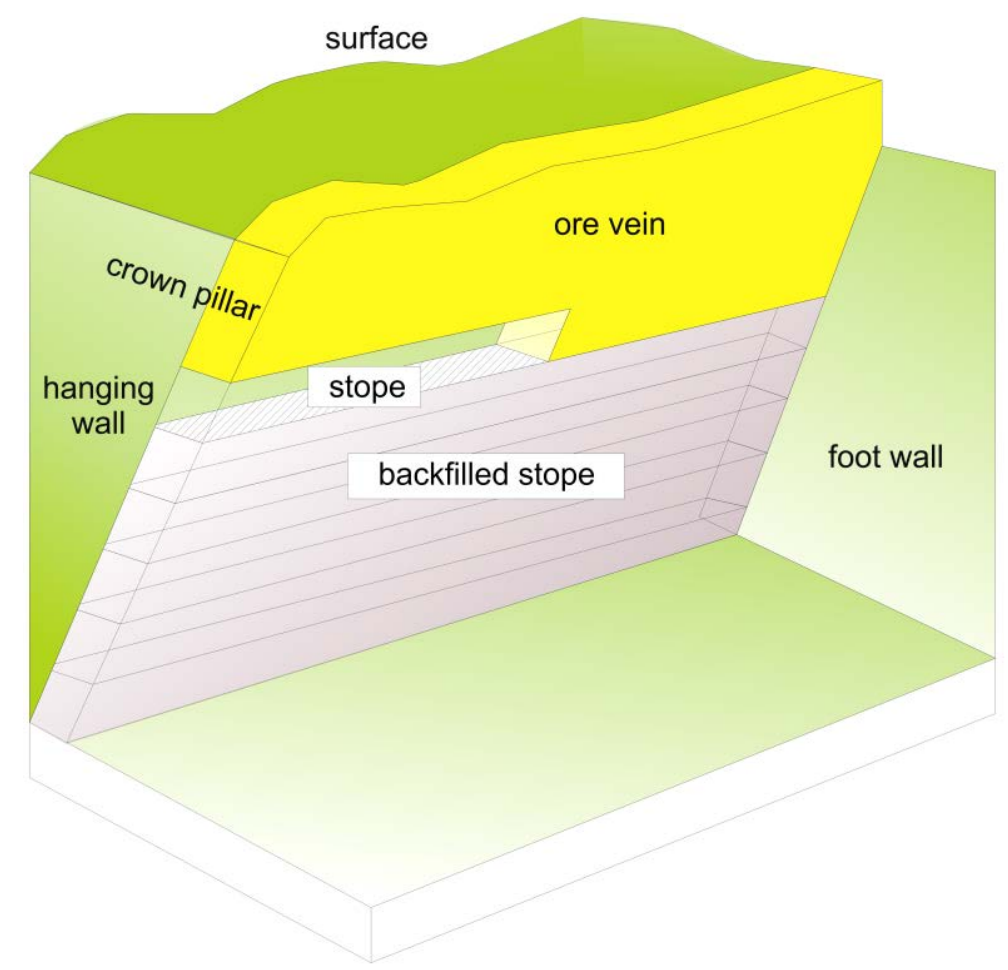

Figure 1. Schematic of overhand cut and fill underground mining method. 
In common practice, increasing crown pillar thickness could be a way to prevent surface subsidence. However, part of crown pillar in overhand cut and fill mining method which is directly above the stope is formed by ore body. Increasing its thickness will increase the stability, yet reduce mining recovery since higher volumes of ore body are left behind as a pillar. Preventing stope failure is the key to maintain stability and to optimize recovery of crown pillar. Therefore, it is important to study countermeasure method for stope failure in crown pillar area to prevent surface subsidence as well as to optimize crown pillar thickness. In this study, an attempt has been made to investigate the effectiveness of various countermeasures for stope failure in crown pillar area of overhand cut and fill underground mine with various geological conditions and stress ratios. The result can be used to design an optimum countermeasure method for stope instability in crown pillar area.

\section{Methodology}

The effectiveness of the countermeasure method for stope failure near surface area was investigated by means of parametric study. A parametric study was carried out on two dimensional finite element numerical model. A 200 meter square numerical model with 5 meter width vein dipping in $75^{\circ}$ as shown in Figure 2 was constructed. Five meter height stope was then constructed from the bottom into the upper part of the vein. This stope will be excavated later in a sequence starting from the bottom level and progressing upwards to simulate overhand cut and fill mining method. The mined out stope will be backfilled by slurry. All material was set to comply with the Mohr-Coulomb failure criterion. The displacement in the lateral limit of the model is only permitted in the $\mathrm{y}$-directions while at the lowest part of the model is only permitted in the x-direction. The surface was set free to move in all directions. Rock mass properties and stress ratio within the model were changed to carry out a parametric study on the numerical model.

Rock mass properties were changed with geological condition as the basis. Geological condition was represented by geological strength index (GSI) parameter [3]. Different GSI values were simulated ranging from 25 , representing disintegrated rock mass with poor joint surface quality, to 75 , representing blocky rock mass with good joint surface quality. The other rock mass properties were then determined for each GSI by using Hoek and Brown Failure Criterion [4]-[6]. The rock mass properties are summarized in the Table 1. Stress ratio during a parametric study of numerical model with different geological conditions was set to be one.

Another modified parameter was the stress ratio $(\mathrm{k})$. The $\mathrm{k}$, ratio of horizontal stress to vertical stress was changed ranging from 0.5 - 2. Stress ratio below one indicates a high vertical stress condition around stope and crown pillar area. On the contrary, stress ratio above one indicates the high horizontal stress condition around stope and the crown pillar area. The rock mass properties used in the parametric study of numerical model with different stress ratio are the one for GSI 50.

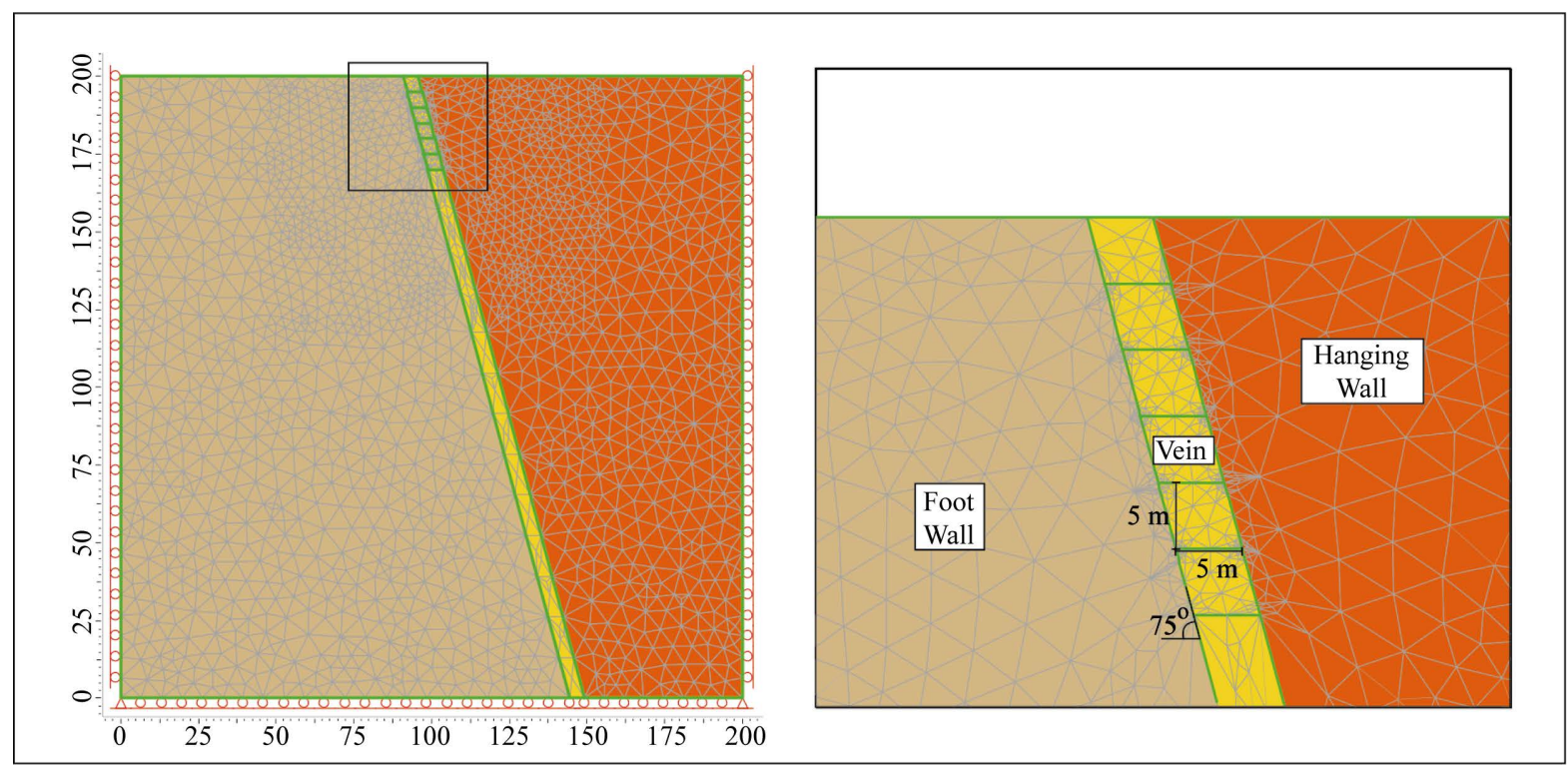

Figure 2. Basic model for parametric study. 
Support system, mainly categorized as active and passive type support [7] [8], along with other proposed countermeasure which are sill pillar and surface pile, will be applied as a countermeasure for stope failure near surface area. Active type support system which is used in the simulation will consist of split set and cable bolt while the passive type support system will consist of shotcrete and H-beam. The properties of split set, cable bolt, shotcrete, H-beam and surface pile are given in Tables 2-6, respectively.

Table 1. Rock mass properties for parametric study of numerical model with different geological conditions.

\begin{tabular}{|c|c|c|c|c|c|c|c|c|c|c|}
\hline \multirow{2}{*}{$\begin{array}{l}\text { Geological Strength } \\
\text { Index (GSI) }\end{array}$} & \multirow{2}{*}{ Zone } & \multicolumn{4}{|c|}{ Hoek Brown Parameter } & \multicolumn{5}{|c|}{ Mohr-Coulomb Parameter } \\
\hline & & $\sigma_{c i}(\mathrm{MPa})$ & $\mathrm{m}_{\mathrm{b}}$ & $\mathrm{s}$ & a & $\mathrm{C}$ (MPa) & $\phi$ & $\sigma_{t}(\mathrm{MPa})$ & $\mathrm{E}_{\mathrm{rm}}(\mathrm{MPa})$ & $\mathrm{v}$ \\
\hline \multirow{3}{*}{25} & Hanging Wall & 2 & 1.71 & 0.00024 & 0.53 & 0.095 & 29.90 & -0.00028 & 47.88 & 0.3 \\
\hline & Footwall & 5 & 1.71 & 0.00024 & 0.53 & 0.13 & 36.73 & -0.0007 & 119.71 & 0.3 \\
\hline & Quartz Vein & 29 & 1.71 & 0.00024 & 0.53 & 0.23 & 49.74 & -0.004 & 694.32 & 0.2 \\
\hline \multirow{3}{*}{37.5} & Hanging Wall & 2 & 2.68 & 0.00096 & 0.51 & 0.12 & 33.55 & -0.00072 & 107.61 & 0.3 \\
\hline & Footwall & 5 & 2.68 & 0.00096 & 0.51 & 0.16 & 40.73 & -0.0018 & 269.025 & 0.3 \\
\hline & Quartz Vein & 29 & 2.68 & 0.00096 & 0.51 & 0.30 & 53.76 & -0.01 & 1560.34 & 0.2 \\
\hline \multirow{3}{*}{50} & Hanging wall & 2 & 4.19 & 0.0038 & 0.50 & 0.145 & 37.19 & -0.0018 & 245.74 & 0.3 \\
\hline & Footwall & 5 & 4.19 & 0.0038 & 0.50 & 0.20 & 44.43 & -0.0046 & 614.37 & 0.3 \\
\hline & Quartz Vein & 29 & 4.19 & 0.0038 & 0.50 & 0.39 & 57.01 & -0.026 & 3563.36 & 0.2 \\
\hline \multirow{3}{*}{62.5} & Hanging Wall & 2 & 6.55 & 0.015 & 0.50 & 0.17 & 40.81 & -0.0047 & 461.26 & 0.3 \\
\hline & Footwall & 5 & 6.55 & 0.015 & 0.50 & 0.24 & 47.92 & -0.011 & 1153.15 & 0.3 \\
\hline & Quartz Vein & 29 & 6.55 & 0.015 & 0.50 & 0.54 & 59.68 & -0.068 & 6688.27 & 0.2 \\
\hline \multirow{3}{*}{75} & Hanging Wall & 2 & 10.23 & 0.06 & 0.50 & 0.21 & 44.33 & -0.012 & 653.08 & 0.3 \\
\hline & Footwall & 5 & 10.23 & 0.06 & 0.50 & 0.31 & 51.14 & -0.03 & 1632.7 & 0.3 \\
\hline & Quartz Vein & 29 & 10.23 & 0.06 & 0.50 & 0.86 & 61.67 & -0.17 & 9469.66 & 0.2 \\
\hline
\end{tabular}

Notes: $\sigma_{\mathrm{ci}}=$ uniaxial compressive strength of intact rock material; $\mathrm{m}_{\mathrm{b}}$, s, a = material constant for Hoek-Brown Failure Criterion; $\mathrm{C}=$ rock mass cohesive strength; $\phi$ = rock mass friction angle; $\sigma_{t}=$ uniaxial tensile strength of rock mass; $\mathrm{E}_{\mathrm{rm}}=$ young modulus of rock mass; $\mathrm{v}=$ Poisson's Ratio.

\section{Table 2. Split set properties.}

\begin{tabular}{cc}
\hline Split Set Properties & 2.4 \\
Length (m) & 46 \\
Diameter (mm) & 178 \\
Typical Tensile Capacity $(\mathrm{kN})$ & 120 \\
Minimum Tensile Capacity $(\mathrm{kN})$ & 200,000 \\
Bolt Modulus (MPa) & 12,000 \\
Bond Shear Stiffness (MN/m/m) & 100 \\
Hot Dip Galvanized $(\mu \mathrm{m})$ & 588 \\
Yield Strength (MPa) & High Strength \\
Type of Steel Material & 53 - 89 \\
\hline
\end{tabular}


Table 3. Cable bolt properties.

\begin{tabular}{cc}
\hline Cable Bolt Properties & \\
Type & Fully Bonded \\
Length (m) & 5 \\
Diameter (mm) & 19 \\
Bolt Modulus (MPa) & 200,000 \\
Tensile Capacity (MN) & 0.1 \\
Residual Tensile Capacity (MN) & 0.01 \\
\hline
\end{tabular}

Table 4. Shotcrete properties.

\begin{tabular}{cc}
\hline Shotcrete Properties & \\
\hline Young Modulus (GPa) & 21 \\
Poisson's Ratio & 0.15 \\
Compressive Strength (MPa) & 35 \\
Tensile Yield (kN) & 20 \\
Residual Yield $(\mathrm{kN})$ & 10 \\
\hline
\end{tabular}

Table 5. H-beam properties.

\begin{tabular}{cc}
\hline H-Beam Properties & \\
\hline Young Modulus (GPa) & 200 \\
Poisson’s Ratio & 0.3 \\
\hline
\end{tabular}

Table 6. Surface pile properties.

\begin{tabular}{cc}
\hline Surface Pile Properties & \\
\hline Length (m) & 5 \\
Tensile Capacity (MN) & 0.178 \\
Bolt Modulus (MPa) & 200,000 \\
Bond Strength (MN/m) & 0.17 \\
Bond Shear Stiffness $(\mathrm{MN} / \mathrm{m} / \mathrm{m})$ & 1500 \\
\hline
\end{tabular}

\section{Results and Discussions}

\subsection{Parametric Study of Numerical Model with Different Geological Condition}

Parametric study in this section is carried out to understand the effectiveness of the countermeasure method for stope failure in different geological conditions. Overall, there are 5 different numerical models simulated with different rock mass properties. Simulation result of 5 different numerical models is compared with each other to obtain a general conclusion of countermeasure effectiveness in different geological conditions.

\subsubsection{Geological Strength Index (GSI) 25}

Simulation result of stope supported by the active type support system for a model with GSI 25 is given in the Figure 3. The color indicates yielded element contour. The zones in which the stress satisfies the yield criterion are considered as yielded element. By looking at the whole pattern of this yielded element, the failure of a stope 


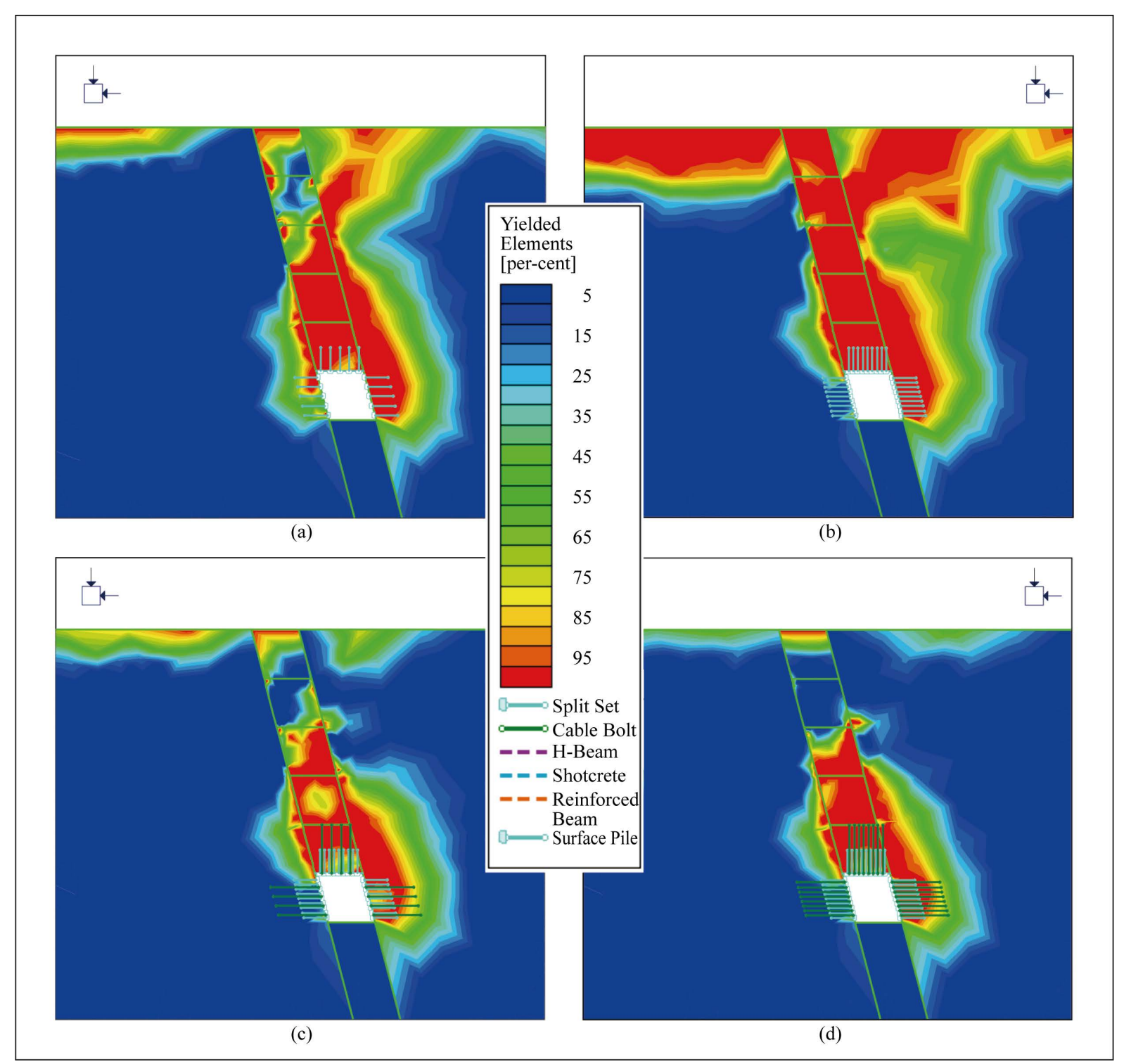

Figure 3. Simulation result of stope supported by the active type support system for a model with GSI 25.

or the crown pillar can be determined. A crown pillar is assumed to be a failure when yielded elements propagate from the stope until the surface area. If the yielded elements only occur around the stope without propagating until surface, it means that failure only occurs at stope.

Simulation result in Figure 3(a) and Figure 3(b) shows crown pillar failure occurs when stope is supported by split set with $1 \mathrm{~m} \times 1 \mathrm{~m}$ and $0.5 \mathrm{~m} \times 0.5 \mathrm{~m}$ spacing, respectively. When combination between split set and cable bolt is installed (Figure 3(c) and Figure 3(d)), yielded element is reduced up to certain level due to increasing support capacity given by cable bolt. However, stope failure still occurs. The active type support system cannot give proper support capacity for stope in severe geological condition. Hence, passive type support system was installed. The result is summarized in Figure 4.

After supported by the shotcrete or H-beam, large yielded zone at roof still occur as shown in Figure 4(a) and Figure 4(b). Stope is still in unstable condition. Nevertheless, there is a reduction of yielded zone surrounding the stope due to higher support capacity given by those two kinds of passive type support system. It means a higher supporting capacity is needed. To give higher supporting capacity, another passive type support system with higher supporting capacity than shotcrete and H-beam, reinforced beam, is simulated as can be seen in Figure 4(c). Reinforced beam is constructed from a combination of shotcrete and H-beam which result in higher 


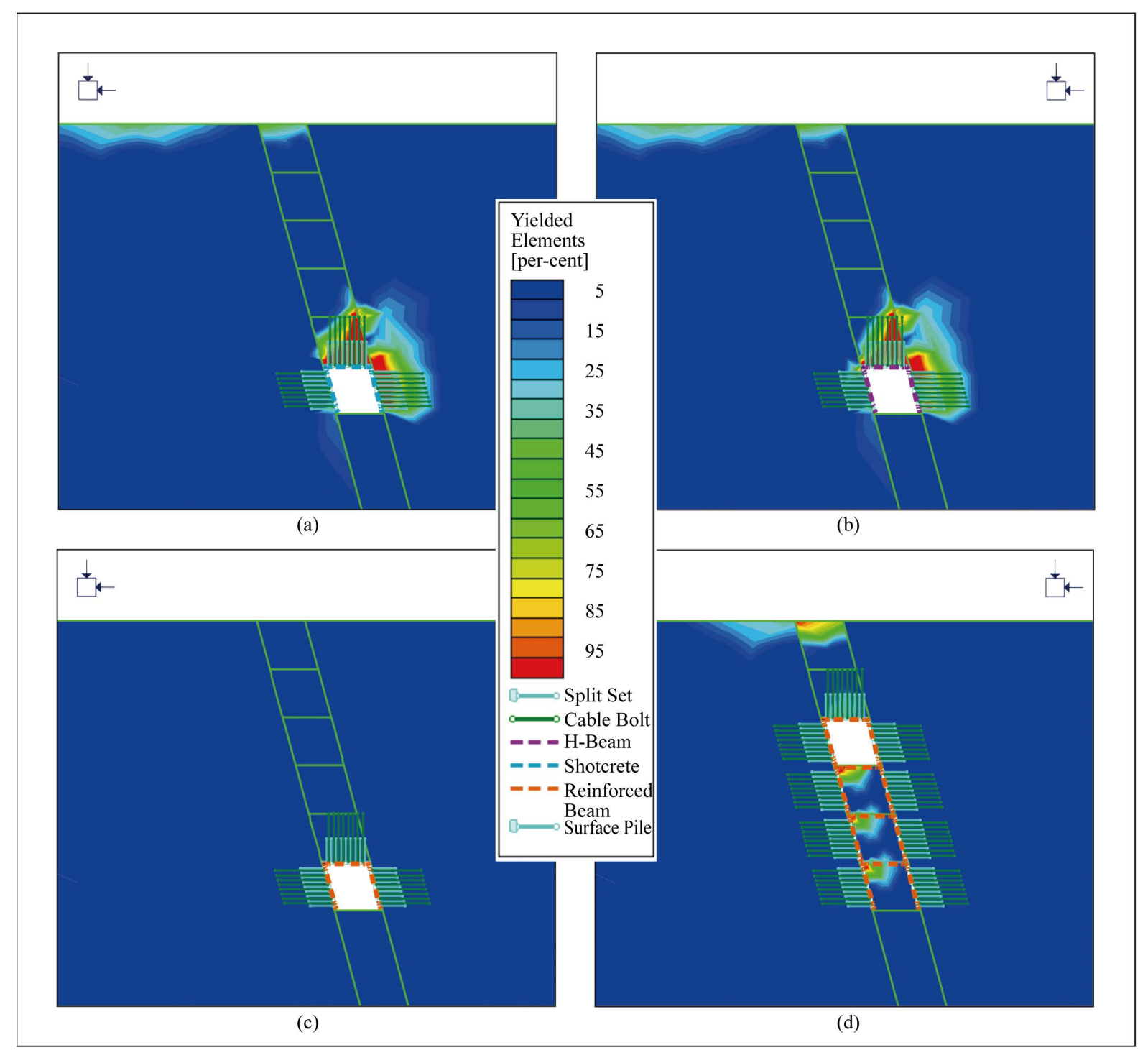

Figure 4. Simulation result of stope supported by the passive type support system for a model with GSI 25.

supporting capacity. From Figure 4(c), it can be seen that stope in the first slice is in stable condition. The simulation result shows that stoping supported by reinforced beam can be carried out until the fourth slice (Figure 4(d)). When the fifth slice is executed, the crown pillar shows the occurrence of failure. Therefore, the optimum crown pillar thickness is 10 meter with the support system design shown in Figure 4(d).

Reinforced beam has the highest supporting capacity among the other previously simulated support system. However, it is also the most expensive one since it combines both shotcrete and H-beam. As a result, economical aspects must be considered when applying this kind of support system, especially when the ore grade is low. The application of reinforced beam will be omitted in the following simulation due to its high cost. Another countermeasure method with a lower cost will be introduced as an alternative method to stabilize stope near surface area.

\subsubsection{Geological Strength Index (GSI) 37.5}

Figure 5 shows simulation results of stope supported by the active type support system for a model with GSI 37.5. Since this model has a better rock mass properties compared with the previous model with GSI 25, supporting capacity needed to support the first slice is not as much as the one in the previous model. The first slice can be supported by split set with $1 \mathrm{~m} \times 1 \mathrm{~m}$ spacing as given in Figure 5(a). A small portion of yielded element 


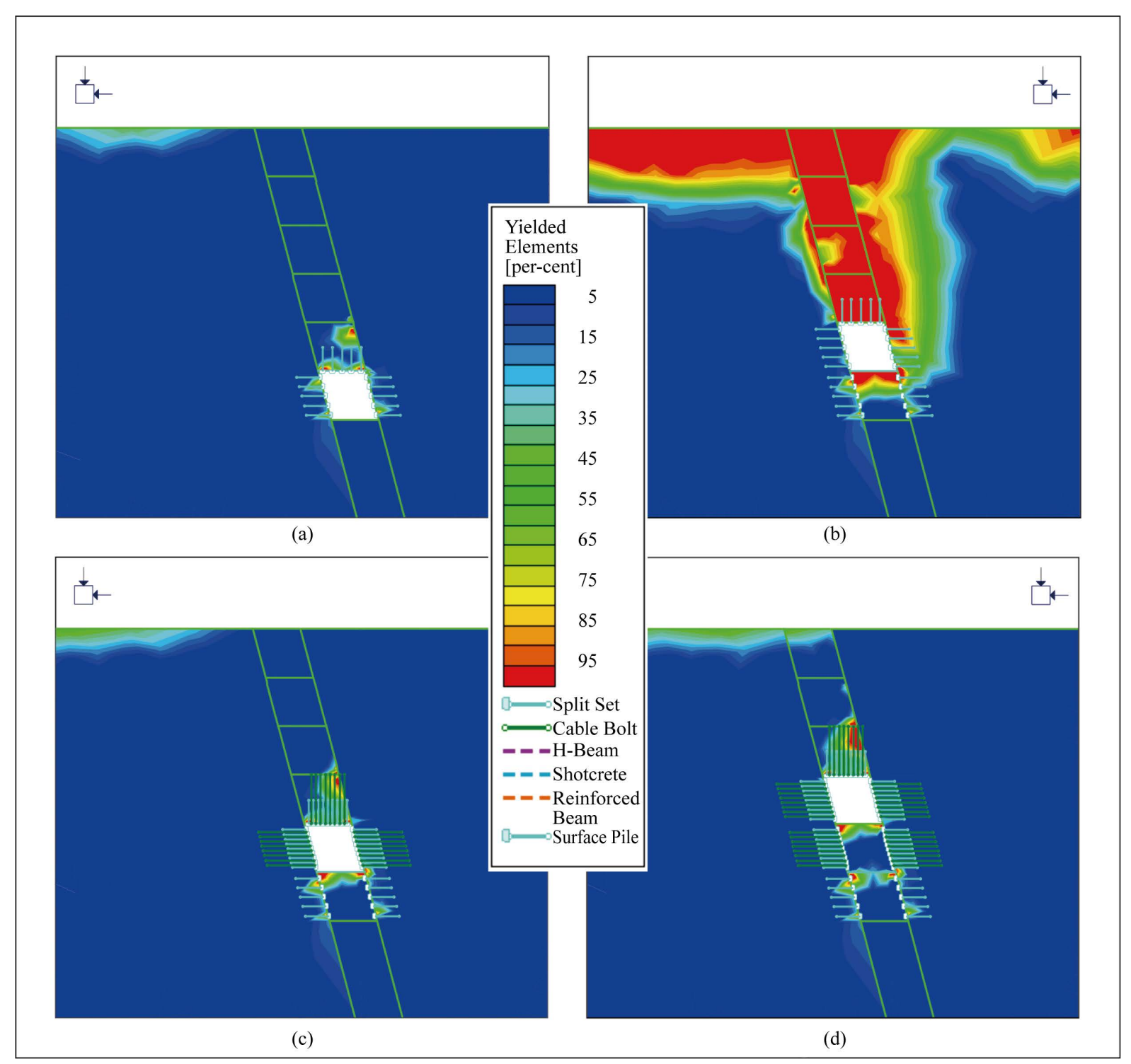

Figure 5. Simulation result of stope supported by the active type support system for a model with GSI 37.5.

occurs on the roof, but since most of the yielded elements is not fully yielded element (100\%—indicates by red color) it can be considered that the stope is in stable condition.

As the stope progressing upwards in Figure 5(b), the induced stress becomes higher because of the accumulation of induced stress from first slice and the second slice. This has caused stope in the second slice failure if the same support system with the previous slice is installed. Addition of cable bolt with $0.5 \mathrm{~m} \times 0.5 \mathrm{~m}$ spacing along with tighter split set in Figure 5(c) can stabilize the second slice. However, failure occurs when the same support system design is installed to support the third slice as can be seen in Figure 5(d). This result clearly shows that as stope progressing upwards more supporting capacity is needed to stabilize the stope.

The application of the passive type support system in stabilizing third slice and its upper slice is given in Figure 6. Figure 6(a) shows addition of shotcrete in third slice can stabilize the stope with only a small portion of fully yielded zone occurs at stope roof. However, when the same support system design applied at the fourth slice, both stope and also the crown pillar failure can be seen, as shown in Figure 6(b). The installation of H-beam instead of shotcrete in the fourth slice also cannot stabilize the stope and crown pillar as shown in Figure 6(c). Based on the simulation result of stope supported by active and passive type support system, the optimum crown pillar thickness is $15 \mathrm{~m}$ with the supporting system design shown in Figure 6(a). 


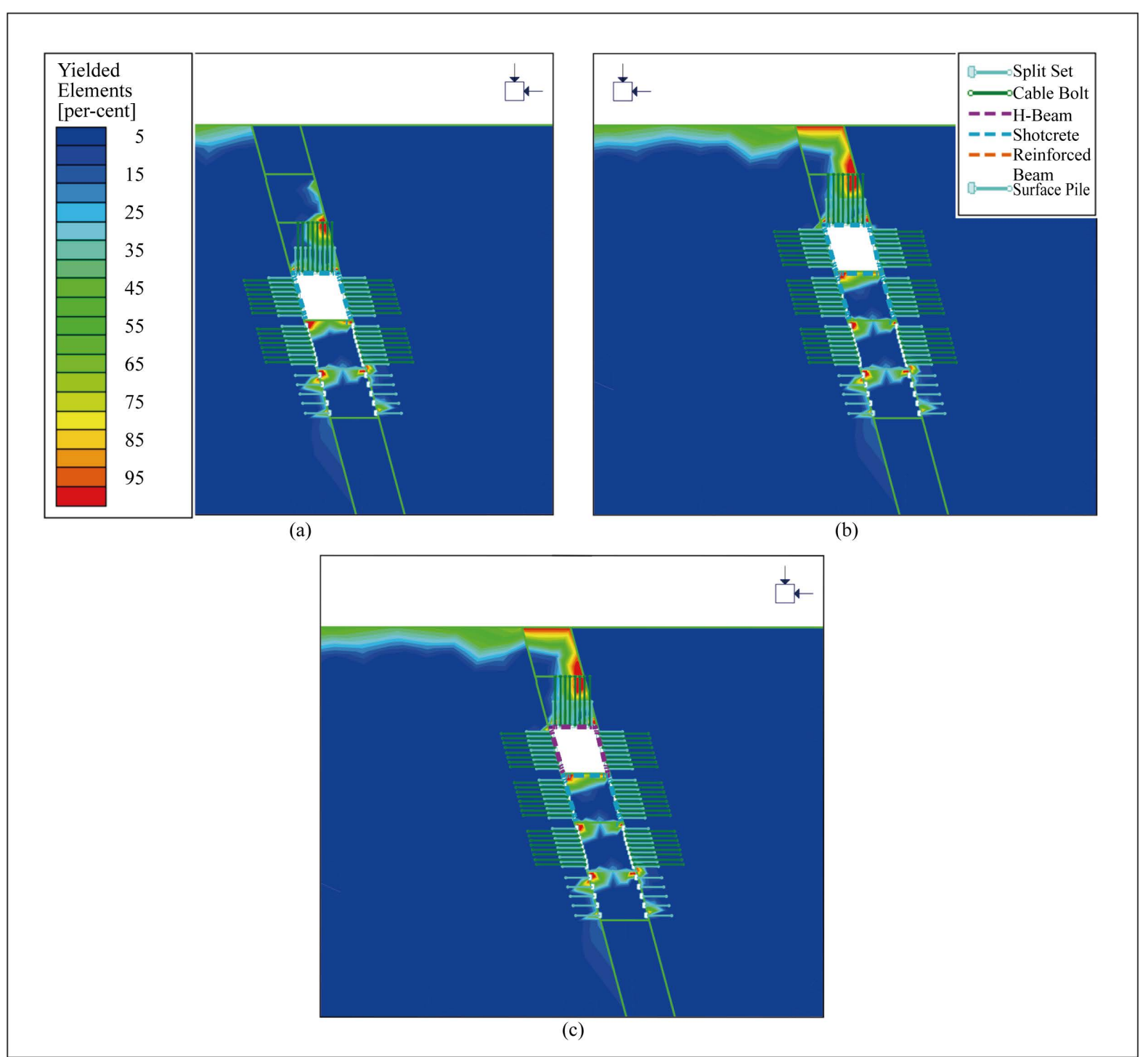

Figure 6. Simulation result of stope supported by the passive type support system for a model with GSI 37.5.

The result of previous simulation shows that the optimum crown pillar for given rock mass properties is 15 meter thickness. Since there is still 15 meter thickness, there is still a possibility to optimize crown pillar thickness. Another countermeasure method is proposed and its simulation result can be seen in Figure 7.

The first proposed countermeasure method is sill pillar. Sill pillar can be applied by abandoning uppermost unstable slice, from previous simulation with active and passive type support system, as a pillar. Mining is continued above the abandoned slice. Schematic of sill pillar application is shown in Figure 7(a). The simulation result of the sill pillar application as a countermeasure method for stope failure in the crown pillar area is given in Figure 7(b). The figure shows there are fully yielded zone occur at the surface. However, the fully yielded zone does not continue to the stope or isolated. Therefore, it can be interpreted that crown pillar is in stable condition. Sill pillar application reduces the accumulated induced stress from the bottom stope. Therefore, the stope above sill pillar is in stable condition. By applying sill pillar, another slice can be mined in the crown pillar area which means optimization of crown pillar thickness is achieved.

Another proposed countermeasure is by installing surface pile from the surface. Since stoping in the crown pillar area is carried out at shallow depth, there is a possibility to install pile from the surface. A 5 meter length surface pile is installed and the simulation result is shown in Figure 7(c). It can be seen clearly that application of surface pile improves the condition of the crown pillar compared to the condition shown in Figure 6(c). Further 


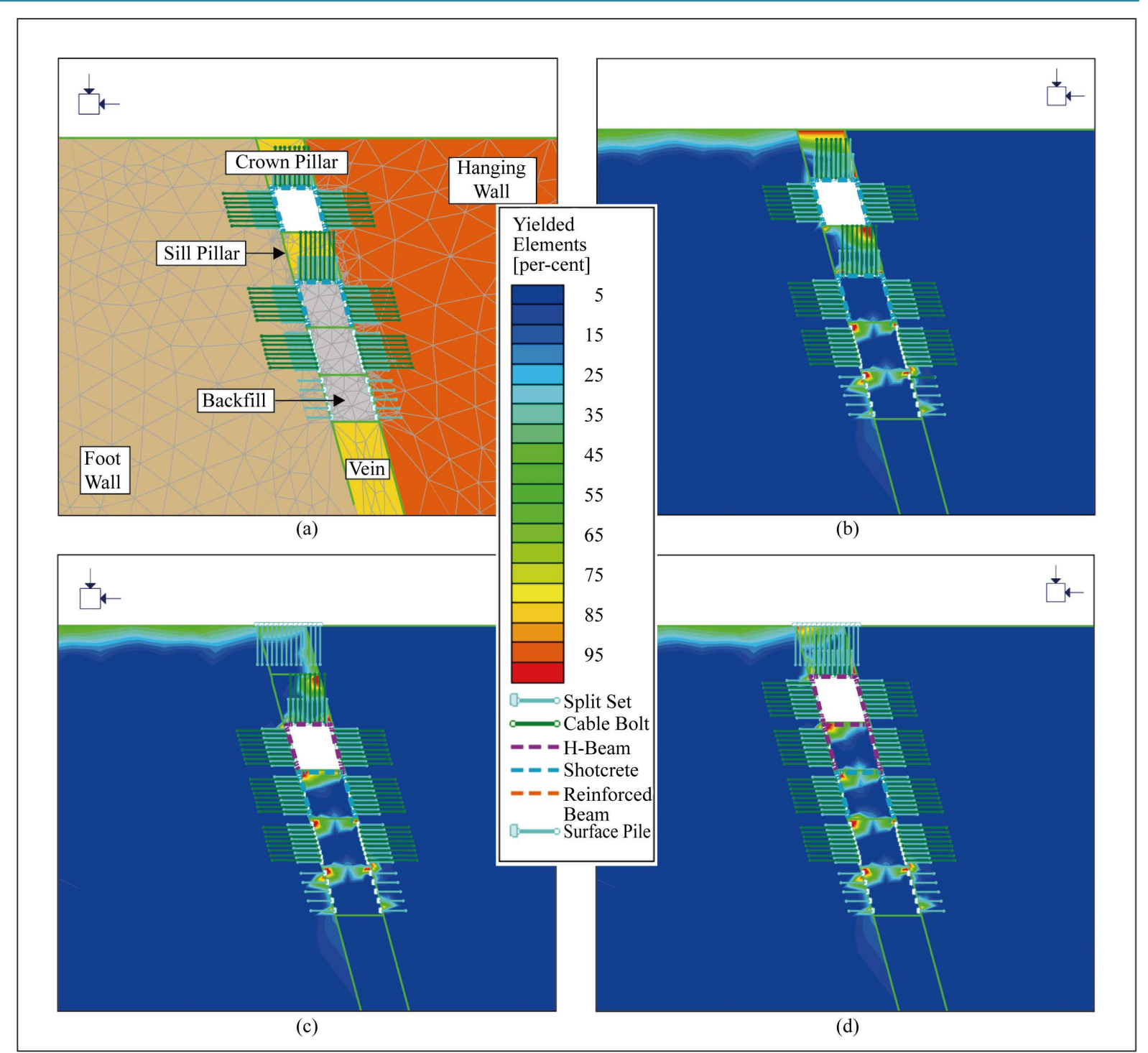

Figure 7. The effect of sill pillar and surface pile to stope and crown pillar stability for a model with GSI 37.5.

analysis in Figure 7(d) shows that upper slice also can be executed with no significant yield zone occur at the crown pillar. Therefore, the application of surface pile can optimize the crown pillar thickness from $15 \mathrm{~m}$ into 5 m.

\subsubsection{Geological Strength Index (GSI) 50}

A series of simulation for model with GSI 50 was carried out. Simulation result of stope supported by the active type support system is given in Figure 8. Comparing with the result in Figure 5, it can be seen clearly that active type support system application is more effective in the model with GSI 50. Figure 8(a) show split set with $1 \mathrm{~m} \times 1 \mathrm{~m}$ spacing can support the first and second slice. Roof failure at stope occurs when the same support system design applied at third slice as shown in Figure 8(b). Further analysis has shown increasing the split set density into $0.5 \mathrm{~m} \times 0.5 \mathrm{~m}$ can stabilize stope at third slice. Both fourth slice and fifth slice can be supported by a combination of split set with $0.5 \mathrm{~m} \times 0.5 \mathrm{~m}$ spacing and cable bolt with $1 \mathrm{~m} \times 1 \mathrm{~m}$ spacing as shown in Figure 8(c) and Figure 8(d). This result suggests that no passive type support system is needed to support stope in this model. Optimum crown pillar thickness is 5 meter based on this simulation.

Better rock mass condition is the reason why no passive type support system is required to support this model compare with the previous model with GSI 37.5. Thus, supporting capacity needed to stabilize stope is reduced. 


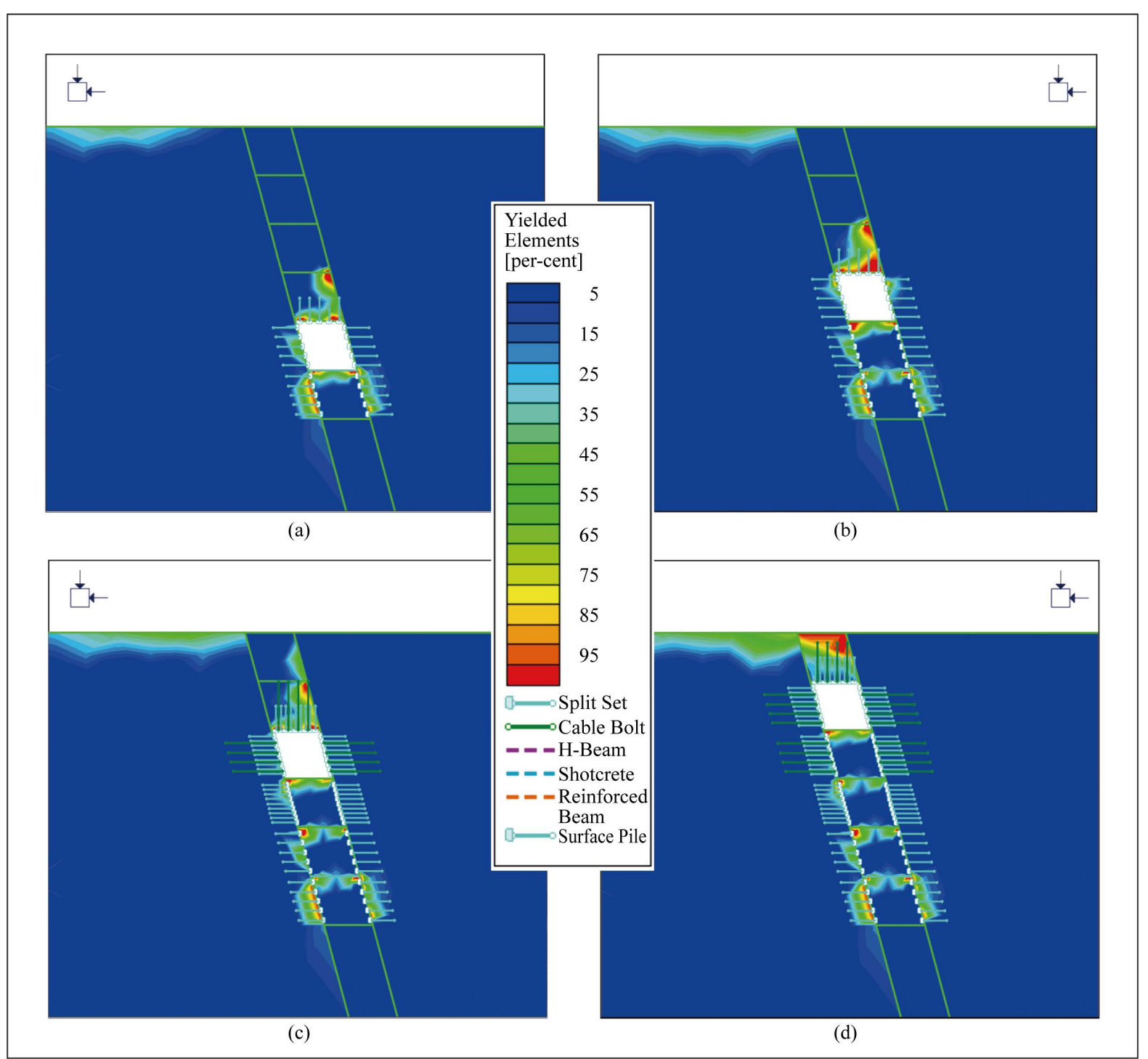

Figure 8. Simulation result of stope supported by the active type support system for a model with GSI 50.

Moreover, this result also strengthening the previous statement that as stope progressing upwards, more supporting capacity is needed. Stope at lower level needs less active type support system than the upper one.

\subsubsection{Geological Strength Index (GSI) 67.5 and 75}

Last parametric study of numerical model with different geological conditions was carried out for models with GSI 67.5 and 75. These two GSI values represent relatively very blocky to blocky rock mass with fair to good joint surface quality. Nevertheless, the rock mass properties are still better than the previous three models. Figure 9 shows simulation results of stope with an active type support system for these two models.

It can be seen clearly that supporting capacity required to stabilize stope is reduced. Split set with $1 \mathrm{~m} \times 1 \mathrm{~m}$ spacing in Figure 9(a) can support the third slice for a model with GSI 67.5. In Figure 8(b), split set with the same spacing cannot be applied to support the third slice for a model with GSI 50. Moreover, 5-meter thickness crown pillar is in stable condition with just supported by $1 \mathrm{~m} \times 1 \mathrm{~m}$ spacing split set as can be seen in Figure 9(b). Similar results are shown for the model with GSI 75 as shown in Figures 9(c) and Figure 9(d). The yield zone contour throughout the model is better than the one in Figure 9(a) and Figure 9(b).

From the simulation result of the model with different geological conditions, it can be concluded that in more severe geological condition, more supporting capacity is needed to stabilize stope. Simulation result of model 


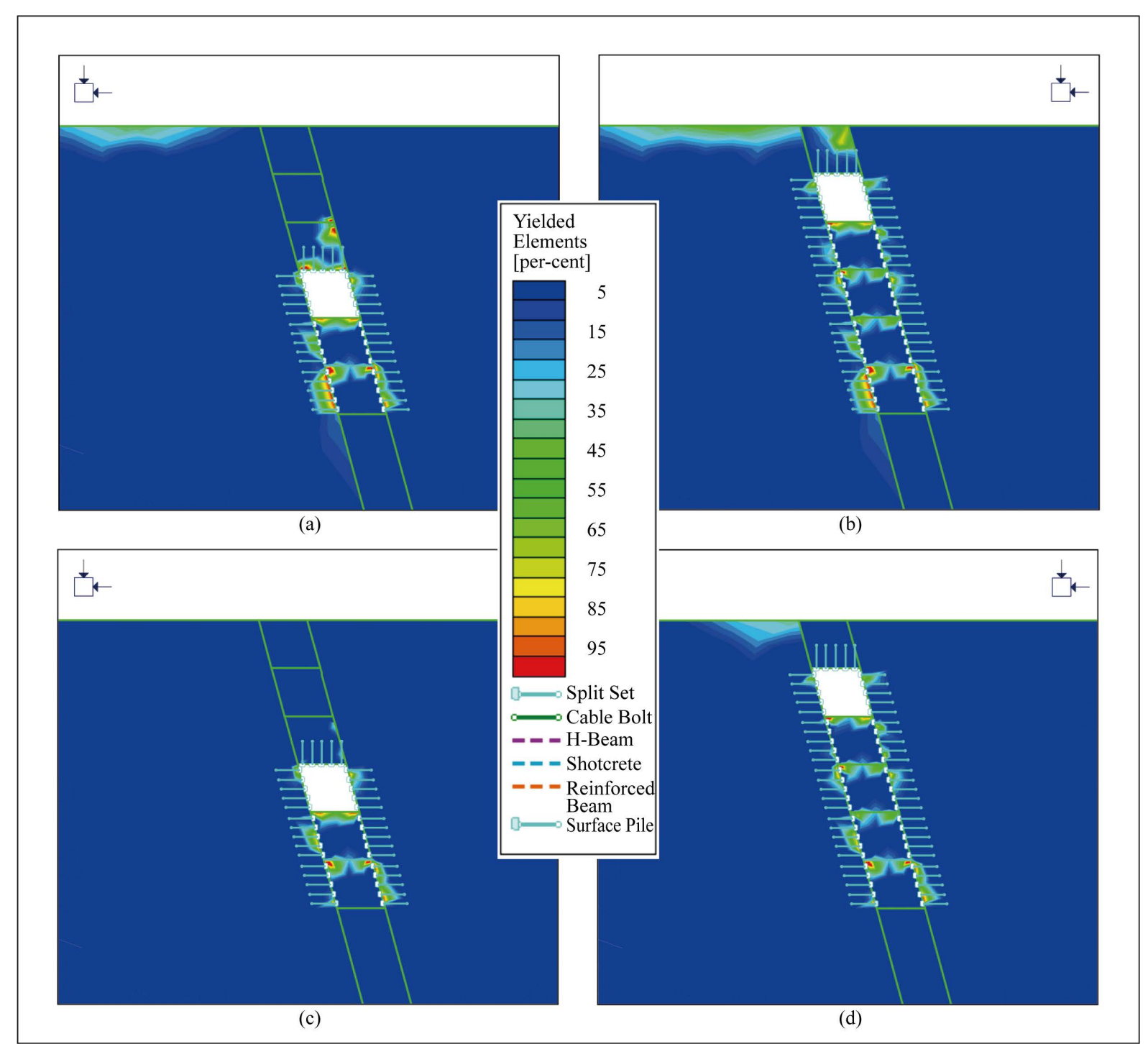

Figure 9. Simulation result of stope supported by the active type support system for a model with GSI 67.5 ((a) and (b)) and GSI 75 ((c) and (d)).

with GSI 25 shows that strongest passive type support which is reinforced beam need to be installed to stabilize stope from the first slice. As simulation is carried out for stronger rock mass, i.e. with GSI 37.5 and 50, active type of support system starts to have an effect in stabilizing stope while passive type support is only needed to support stope in the crown pillar area for model with GSI 37.5. For a good rock mass condition with GSI above 50 , only active type support system is needed to stabilize stope in crown pillar and non-crown pillar area.

\subsection{Parametric Study of Numerical Model with Different Stress Ratio (k)}

Parametric study in the following sections was carried out in order to understand the effectiveness of countermeasure method for stope instability under different horizontal stress to vertical stress ratio. In general, the result will be focused to find countermeasure method which effective to be installed in the high vertical stress condition and in high horizontal stress condition.

\subsubsection{Stress Ratio (k) 0.5}

Stope and crown pillar in this simulation is surrounded by condition where the value of vertical stress is twice of horizontal stress. Figure 10 shows simulation results of stope supported by the active type support system. The 


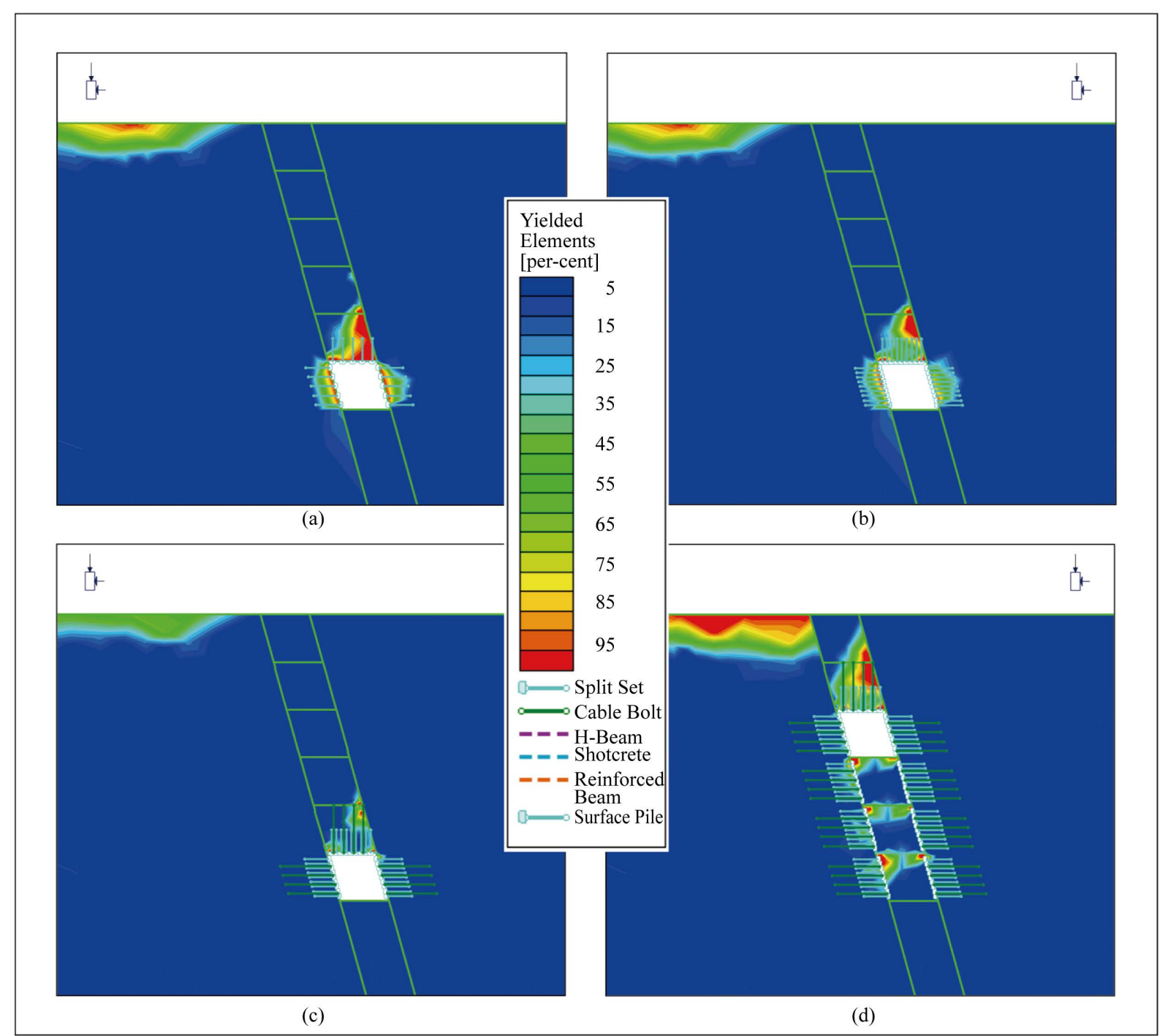

Figure 10. Simulation result of stope supported by the active type support system for a model with stress ratio (k) 0.5 .

split set both with $1 \mathrm{~m} \times 1 \mathrm{~m}$ and $0.5 \mathrm{~m} \times 0.5 \mathrm{~m}$ spacing cannot be applied to support stope at the first slice as shown in Figure 10(a) and Figure 10(b), respectively. A combination of $0.5 \mathrm{~m} \times 0.5 \mathrm{~m}$ spacing split set and 1 $\mathrm{m} \times 1 \mathrm{~m}$ spacing cable bolt need to be applied to support the stope at first slice (Figure 10(c)). Based on the analysis, this combination of support system can support the stope until third slice before finally the stope at fourth slice is unstable as can be seen in Figure 10(d).

To optimize the crown pillar area, passive type support system is installed at stope in fourth slice and the result shown in Figure 11. However, it turns out both shotcrete and H-beam cannot give an improvement to stope condition in the crown pillar area. Therefore, 15 meter crown pillar thickness needs to be spared if it is only active and passive type of support system that considered as a countermeasure method for stope instability.

To optimize 15 meter crown pillar thickness from the previous analysis, another simulation by using sill pillar and surface pile as a countermeasure to stope instability in the crown pillar area was carried out. The simulation result is provided in Figure 12. Figure 12(a) shows the application of sill pillar stabilize stope at fifth slice. Optimum crown pillar thickness with the application of sill pillar is 5 meter with one abandoned slice, the fourth slice. Application of surface pile also gives an improvement by reducing the yielded zone in the crown pillar area as shown by Figure 12(b). However, when the fifth slice is executed, the crown pillar failure can be seen in Figure 12(c). Therefore, the optimum crown pillar thickness if the surface pile is applied as a countermeasure is 10 meter thickness. 


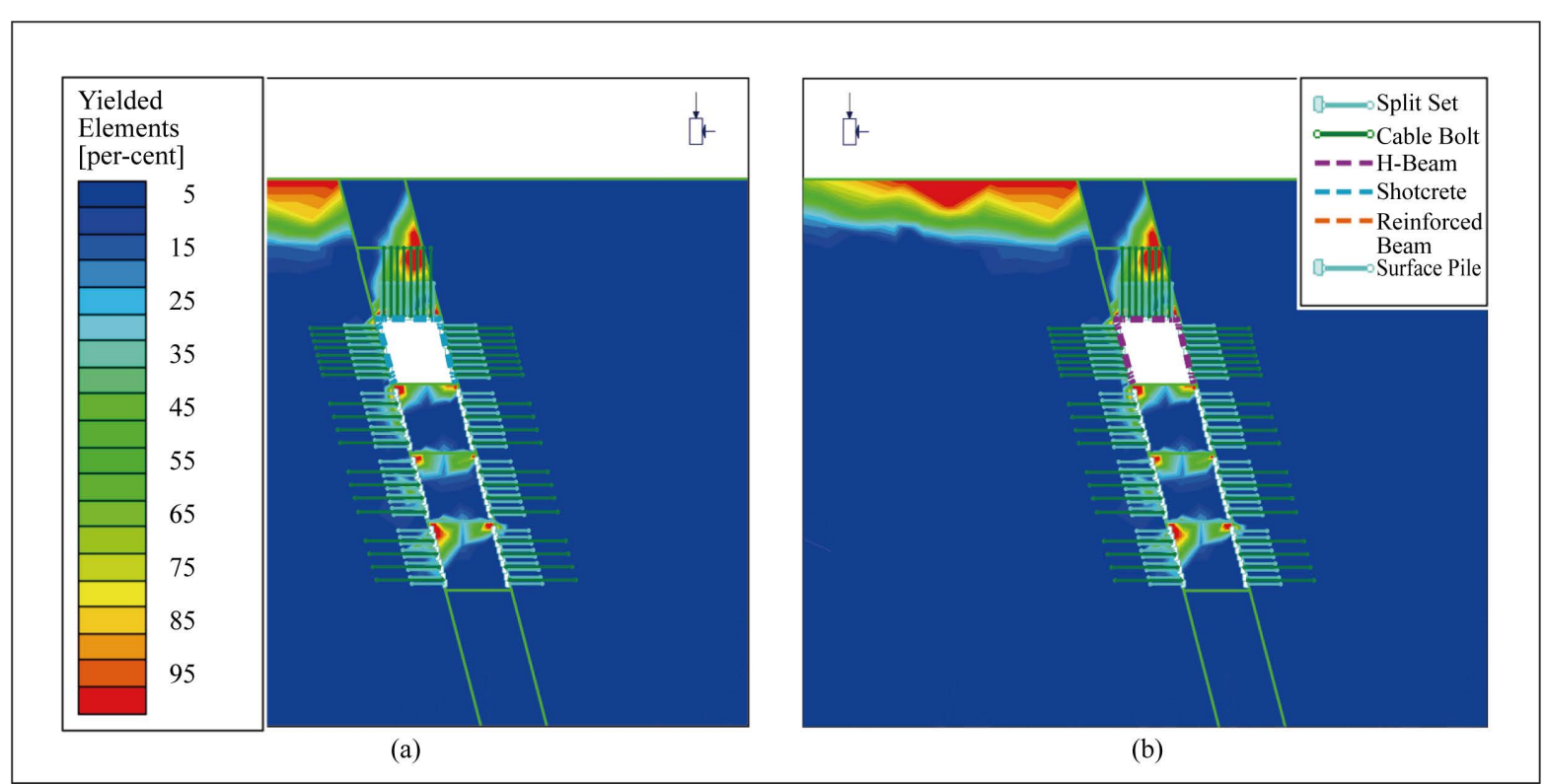

Figure 11. Simulation result of stope supported by the passive type support system for a model with stress ratio (k) 0.5 .

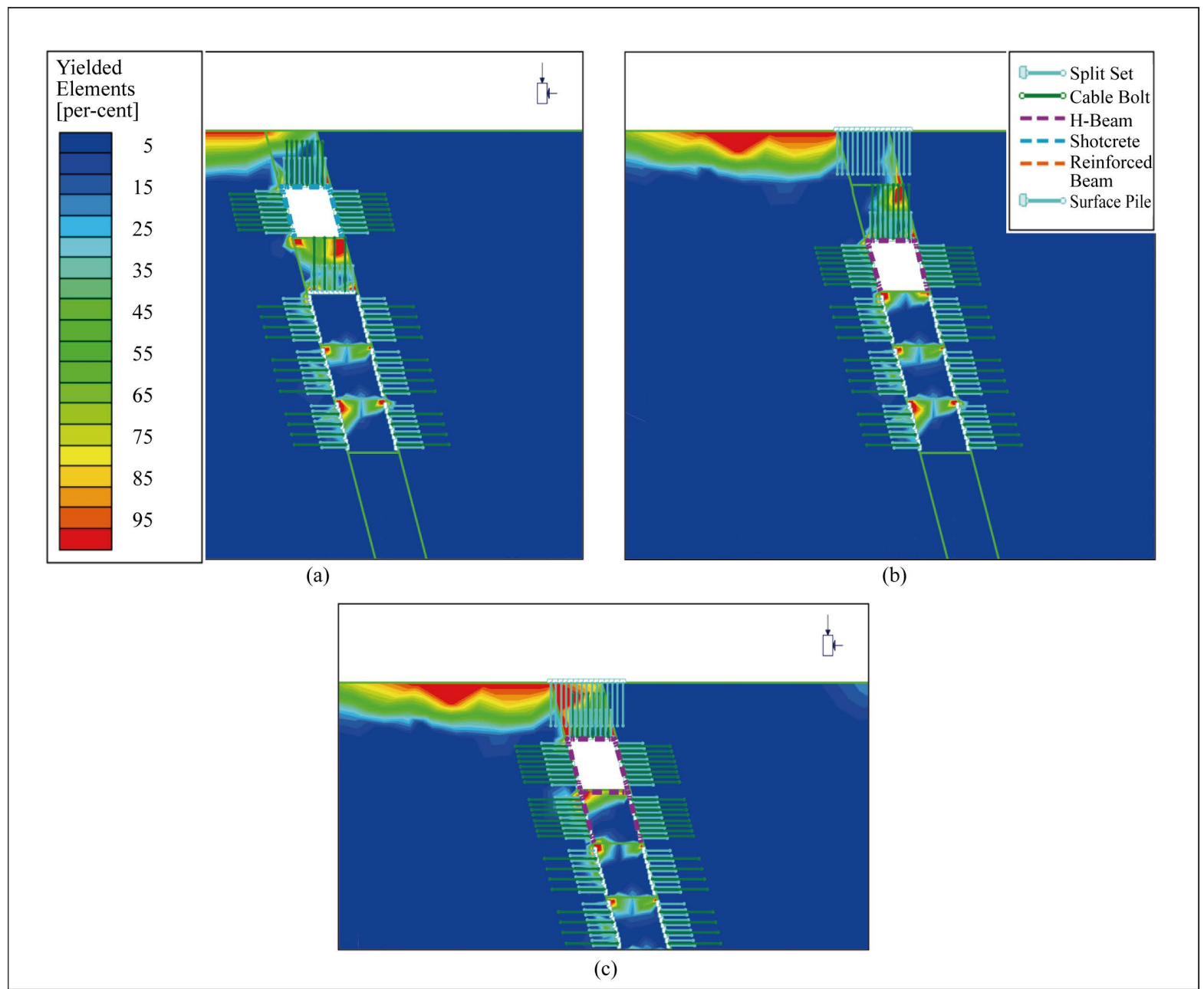

Figure 12. The effect of sill pillar and surface pile to stope and crown pillar stability for a model with stress ratio (k) 0.5 . 


\subsubsection{Stress Ratio (k) 0.75}

Another simulation of model with the high vertical stress condition is carried out with stress ratio 0.75 . The trend as can be seen in Figure 13 is quite similar to the one in Figure 10. Active type support is effective to support the stope in high vertical stress condition. In Figure 13(a), split set with $1 \mathrm{~m} \times 1 \mathrm{~m}$ spacing can support stope until the third slice. There is a reduction of required supporting capacity from the one in Figure 10 where combination of $0.5 \mathrm{~m} \times 0.5 \mathrm{~m}$ spacing split set and $1 \mathrm{~m} \times 1 \mathrm{~m}$ spacing cable bolt needs to be applied. This reduction mainly caused by the reduction of vertical stress value surrounding the stope from the twice of horizontal stress value in model with stress ratio 0.5 becomes 1.3 times of horizontal stress value in the current model. Since both of the models with stress ratio lower than one $(\mathrm{k}<1)$ showed the active type support system can be applied until the third slice, it is worth to mention that the active type support system is effective to be applied in stope with the high vertical stress condition. However, it is not so effective to support stope in the crown pillar area. Increasing density of split set and combine it with cable bolt even with tight spacing cannot improve the stope stability in the crown pillar area as can be seen in Figures 13(b)-(d).

Simulation results of sill pillar and surface pile application as a countermeasure for stope instability in the crown pillar area as shown in Figure 14 is also similar to those in Figure 12. Sill pillar stabilizes stope in crown pillar area as shown in Figure 14(a) while surface pile also can improve stope stability when the fourth slice is

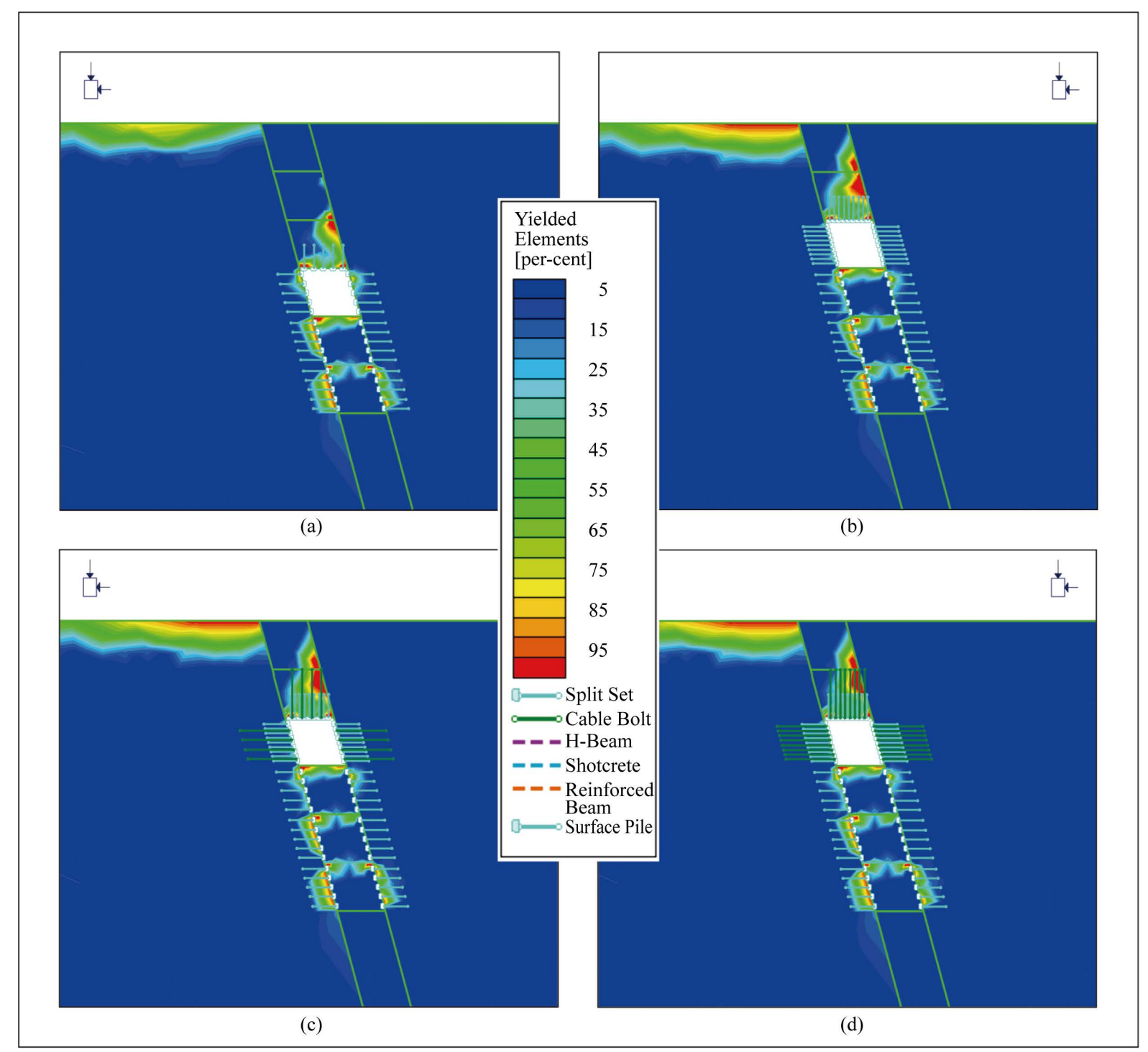

Figure 13. Simulation result of stope supported by the active type support system for a model with stress ratio (k) 0.75 . 


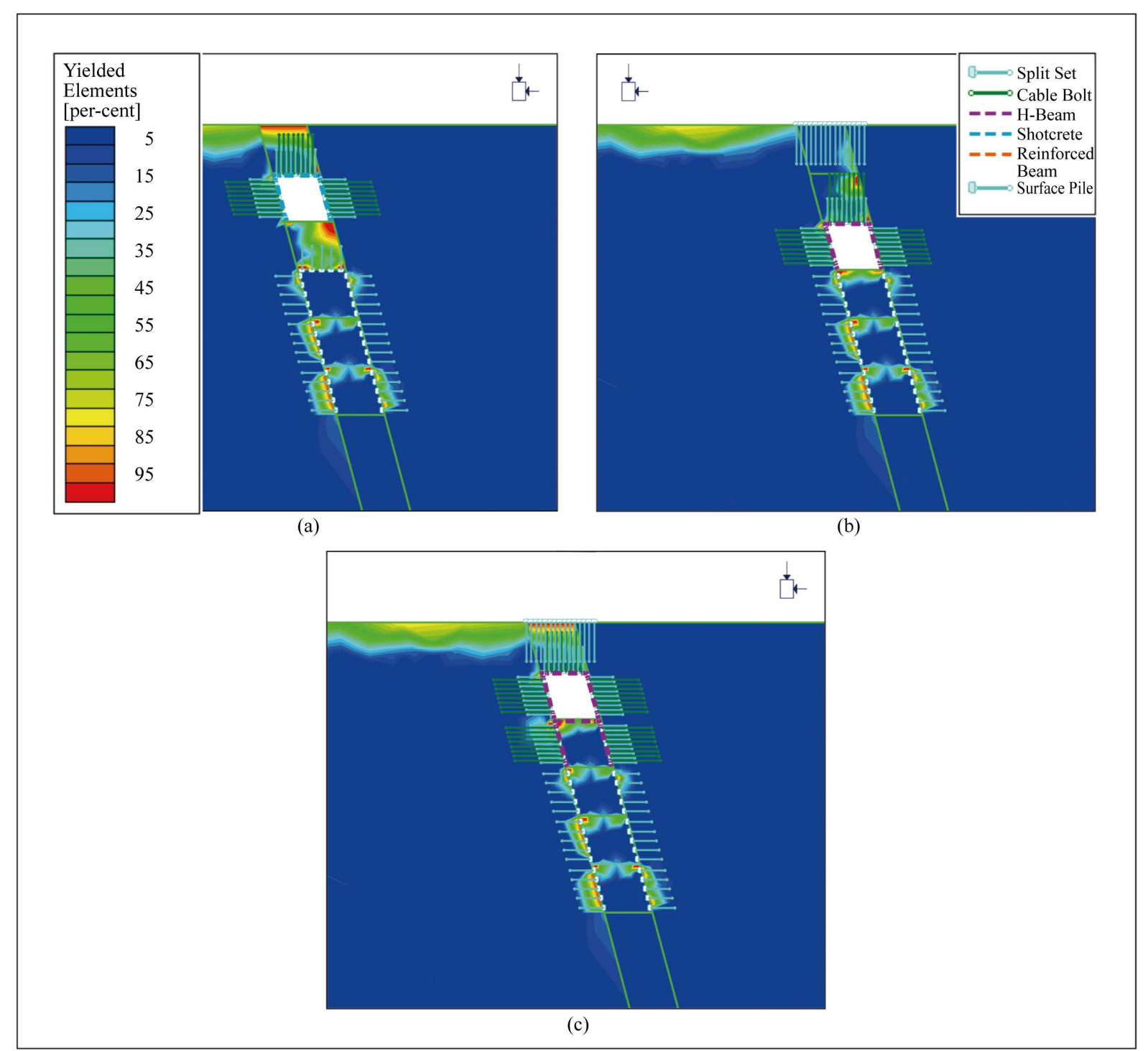

Figure 14. The effect of sill pillar and surface pile to stope and crown pillar stability for a model with stress ratio (k) 0.75 .

executed, shown by Figure 14(b). Moreover, with the application of surface pile, the stope at fifth slice can be executed and crown pillar thickness is optimized into 5 meter thickness. This result is given in Figure 14(c). This improvement, compared to the surface pile effect in Figure 12, occurs due to reduction of vertical stress above the stope at fifth slice.

\subsubsection{Stress Ratio (k) $\mathbf{1 . 5}$}

Simulation result for model with stress ratio 1 is similar to those in section 3.1.3 due to the similar stress ratio and rock mass parameter condition. This section reveals the effectiveness of countermeasure method when applied at stope in areas with a high horizontal stress value which is one and a half of its vertical stress value. The simulation results are given in Figure 15. Split set with $0.5 \mathrm{~m} \times 0.5 \mathrm{~m}$ spacing can only support stope at the first slice (Figure 15(a)). The second slice cannot be executed by using the same split set design and even a combination of split set and cable bolt with tight spacing as revealed in Figures 12(b)-(d). Unlike the simulation result for model with stress ratio below 1, active type support system is not effective to be applied in conditions where high horizontal stress occurs around the stope area.

Passive type support system is then installed from the second slice and the result is shown in Figure 16. The application of shotcrete is proven effective to stabilize stope from the second slice until the fourth slice as can be 


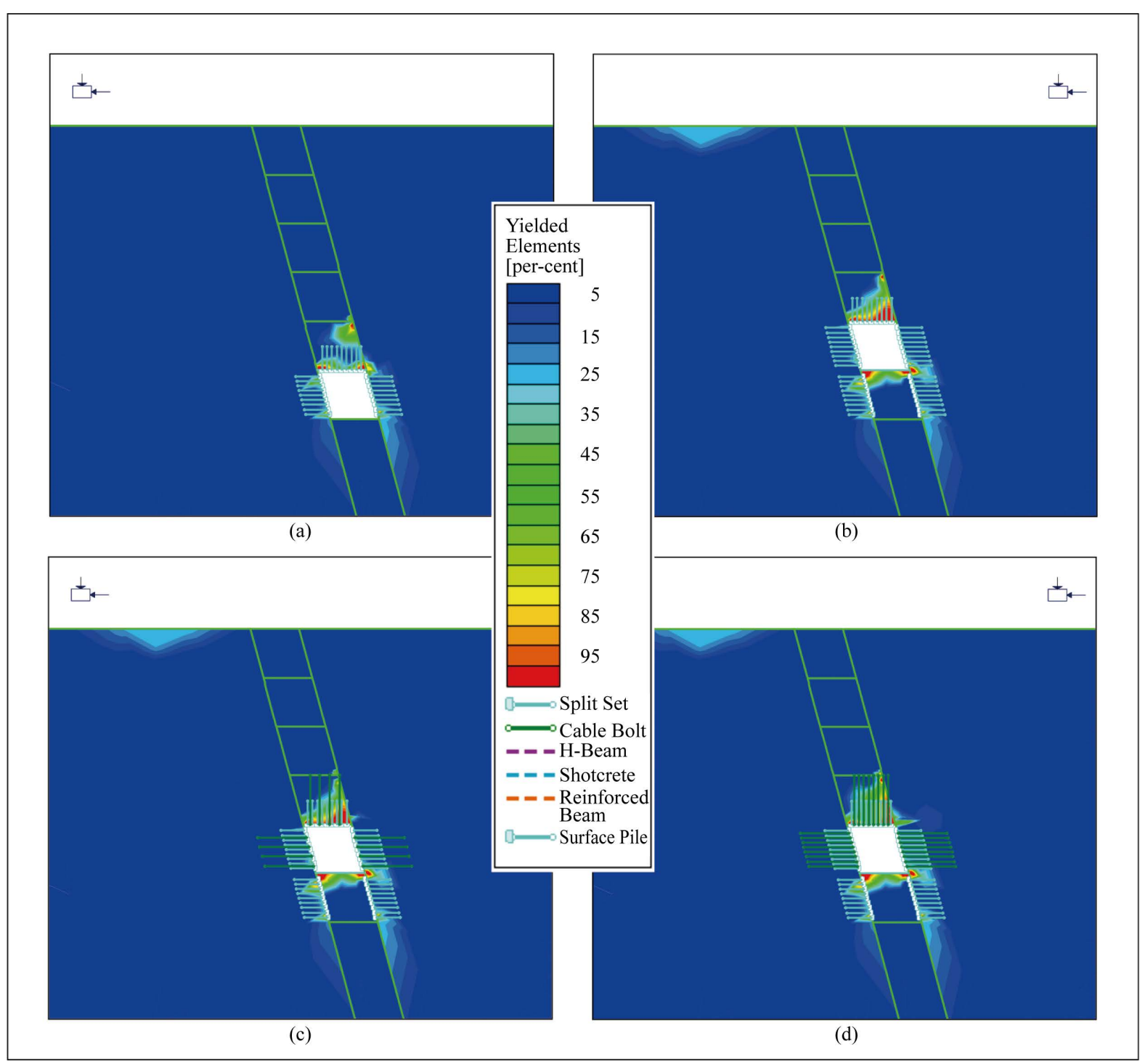

Figure 15. Simulation result of stope supported by the active type support system for a model with stress ratio (k) 1.5 .

seen in Figure 16(a) and Figure 16(b). Crown pillar failure occurs when the fifth slice is executed as shown in Figure 16(c). Figure 16(d) shows H-beam also cannot give a proper supporting capacity for stope and crown pillar at fifth slice. Therefore, the supporting design in Figure 16(b) is considered as an optimum design.

Surface pile is then installed as a countermeasure for stope failure in the fifth slice and the result can be seen in Figure 17. An improvement is made in the crown pillar area with no significant yield zone identified. Sill pillar cannot be applied to this model since the crown pillar thickness is 10 meter. If the fourth slice is abandoned as a sill pillar and the fifth slice is became able to be mined, then it will be even. Therefore, sill pillar is not considered to optimize crown pillar in this model.

\subsubsection{Stress Ratio (k) 2}

Simulation of model with stress ratio 2 was carried out in order to get a clearer trend on the effectiveness of the countermeasure method for stope instability in high horizontal stress condition. Simulation result of stope supported by the active type support system for model with stress ratio 2 is given in Figure 18. The result strengthens the previous statement that the application of the active type support system in this condition is not effective. Even the combination between cable bolt and split set with tight spacing, in Figure 18(c) and Figure 18(d), cannot stabilize the stope at first slice. Failure not only occurs at stope but propagates until surface area. 


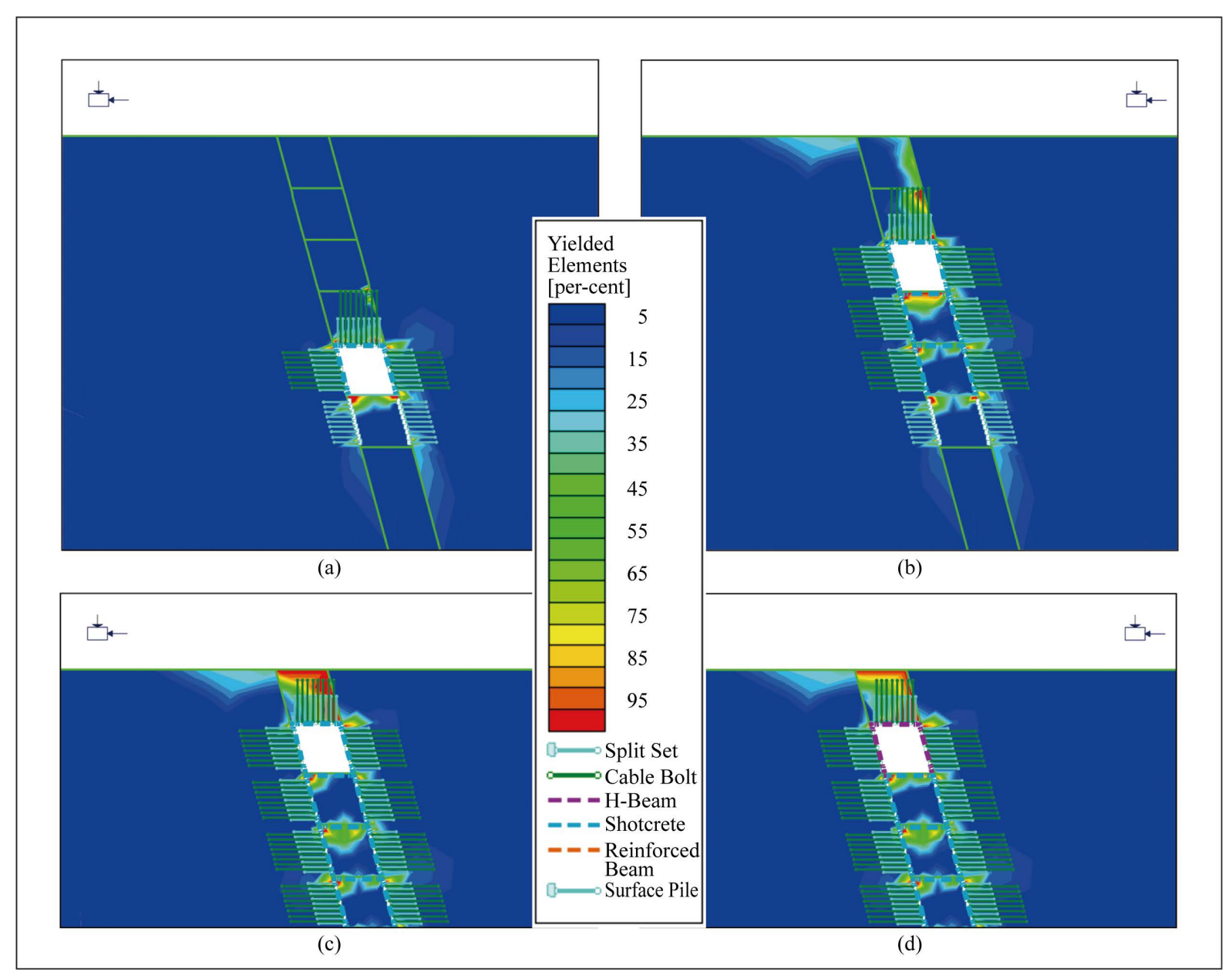

Figure 16. Simulation result of stope supported by the passive type support system for a model with stress ratio (k) 1.5 .

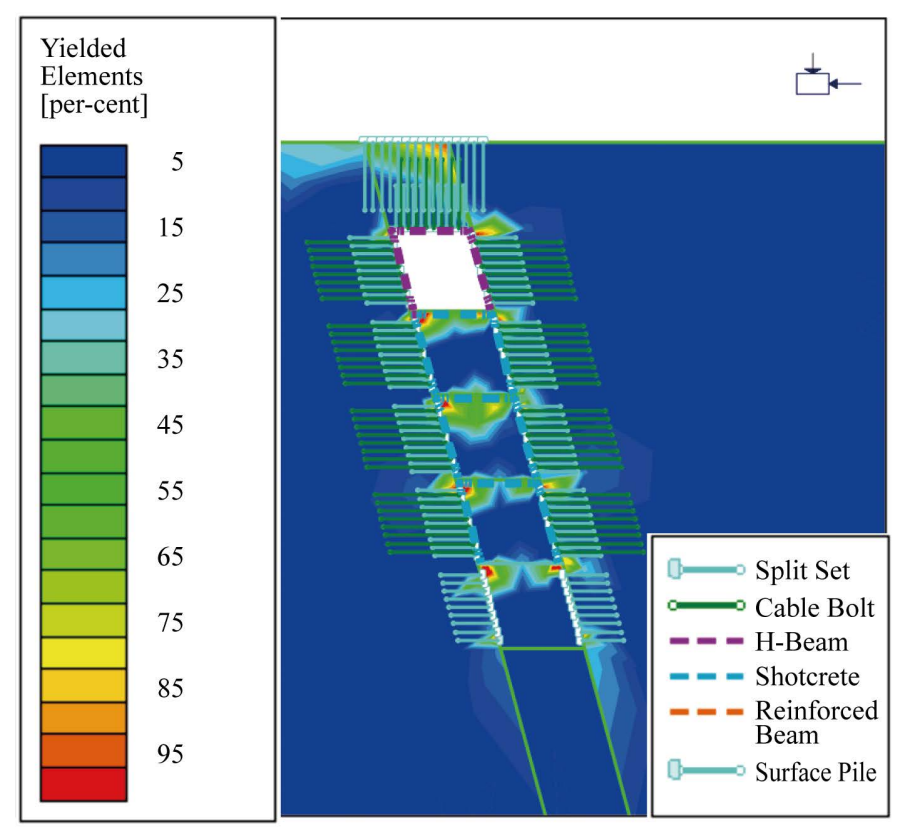

Figure 17. The effect of surface pile to stope and crown pillar stability for a model with stress ratio (k) 1.5. 


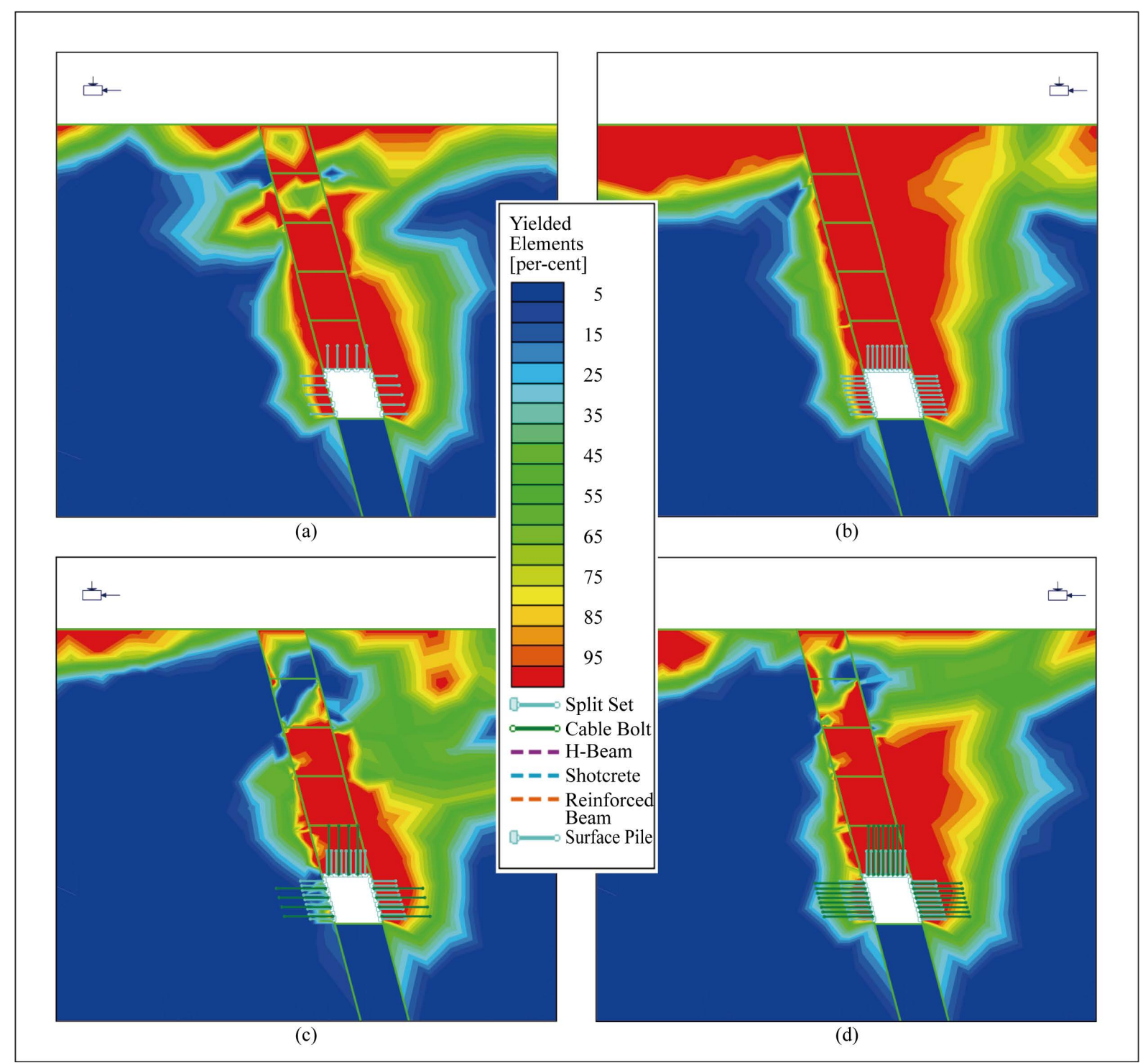

Figure 18. Simulation result of stope supported by the active type support system for a model with stress ratio (k) 2.

Simulation result of passive type support system installation in the model can be seen in Figure 19. Installation of shotcrete can support the stope at first slice as shown in Figure 19(a). However, as it is installed at second slice, failure of the roof occurs as can be seen in Figure 19(b). Figure 19(c) shows the installation of H-beam can give a proper supporting capacity to stabilize the stope at second slice. Nevertheless, instability occurs when the H-beam is installed to support stope at third slice. If considered countermeasure for stope instability is only the active and passive type of support system, then mining should be stopped until the second slice.

To increase ore recovery, sill pillar is applied as an alternative countermeasure. The application of surface pile is limited since the stope is located at depth and not in shallow areas. Therefore, only sill pillar can be applied as an alternative countermeasure to stabilize stope in this condition. The third slice is abandoned as a sill pillar and the result shown in Figure 20. It can be seen that stope at fourth and even fifth slice is in stable condition as presented in Figure 20(a) and Figure 20(b). The crown pillar is also in stable condition. Therefore, it can be concluded that application of sill pillar as an alternative countermeasure is very effective.

\section{Conclusions}

Stoping near the surface area in overhand cut and fill mining method has specific characteristics. As stope 


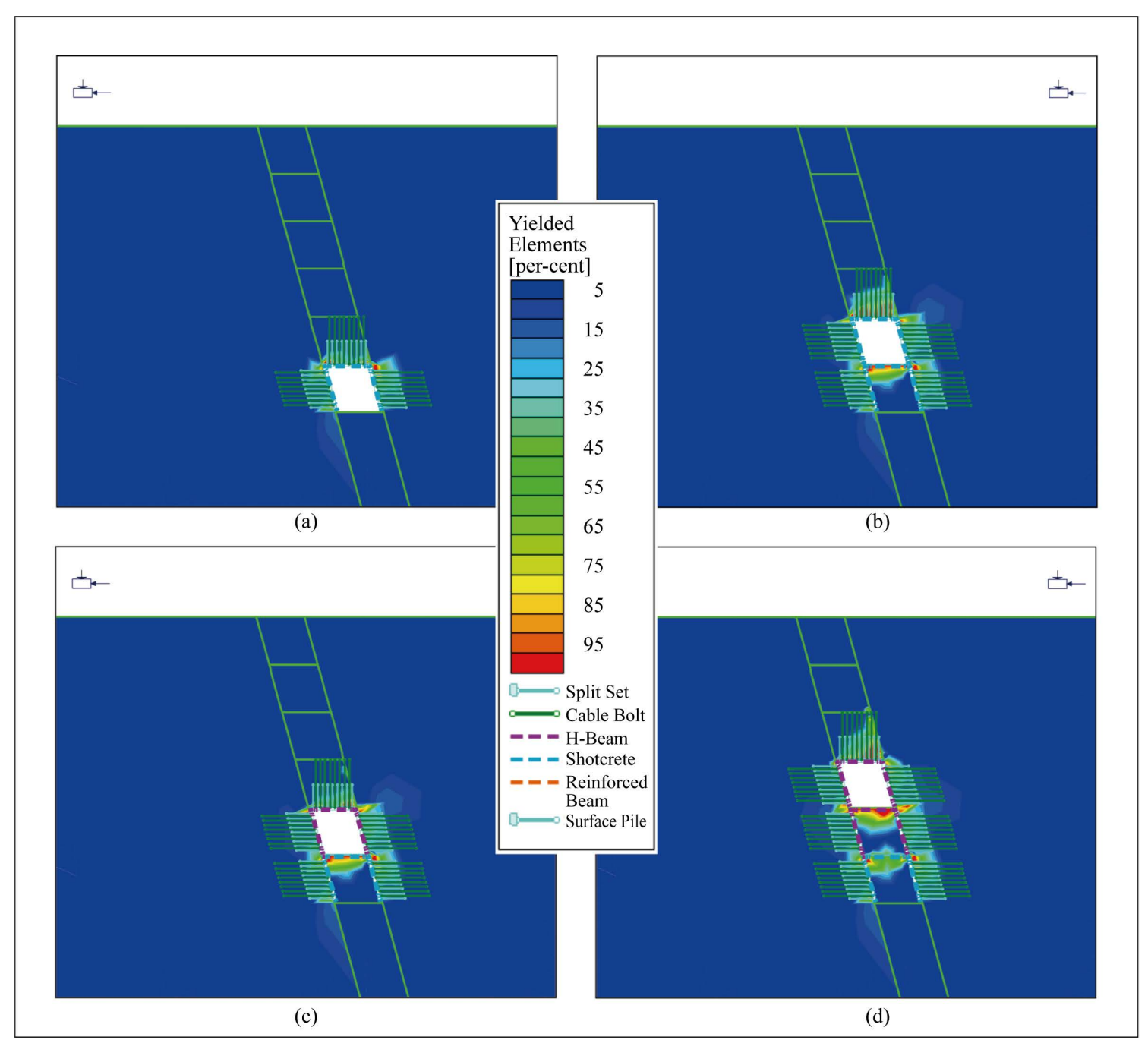

Figure 19. Simulation result of stope supported by the passive type support system for a model with stress ratio (k) 2 .

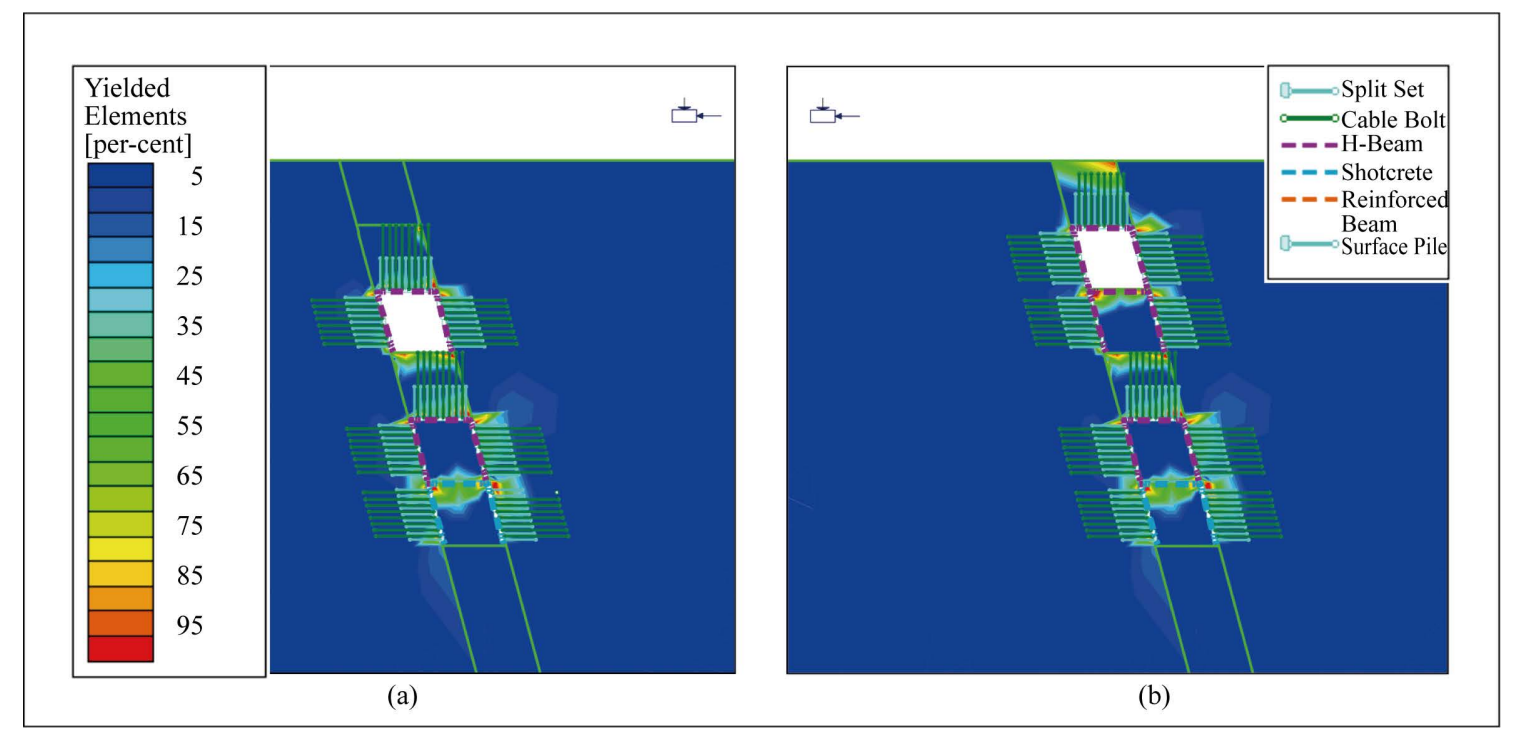

Figure 20. The effect of sill pillar to stope and crown pillar stability for a model with stress ratio (k) 2. 
progressing upwards, accumulation of induced stress becoming higher thus more supporting capacity is needed. Effectiveness of various countermeasure methods for stope instability near surface area has been investigated by means of parametric study. The result shows active type support system is effective for supporting stope in high vertical stress condition while the passive type support system needs to be installed if the stope is opened at high horizontal stress condition. In general, more supporting capacity of both types support system are needed if the stope is opened in more severe geological condition from the result of parametric study with different geological conditions.

Another countermeasures, sill pillar and surface pile, are introduced for stope instability in crown pillar and non-crown pillar area. Sill pillar is abandoned slice of unstable stope from stability analysis. Sill pillar is very effective to stabilize stope both in crown pillar and non-crown pillar area, especially for stope in high horizontal stress condition. Sill pillar application in model with stress ratio 2 can optimize 20 meter thickness of crown pillar into 5 meter. However, abandoning slice means decreasing ore recovery. One should consider applying sill pillar only if sill pillar can generate at least the same amount of ore than the one it abandoned. Surface pile can be installed from surface to improve stability of crown pillar and stope. The most effective use of surface pile is found in simulation of model with stress ratio 0.75 where surface pile can optimize 15 meter thickness of crown pillar into 5 meter. The surface pile application has limitation in depth thus it cannot improve stability of stope located in deeper depth than surface pile length. Each of countermeasure method has its limitation. Nevertheless, with the good understanding of its strength and weaknesses, an appropriate countermeasure method can be applied to maintain stability as well as to optimize recovery of the crown pillar.

\section{Acknowledgements}

The authors would like to acknowledge members of Rock Engineering Laboratory of Kyushu University, Mine Planning Laboratory of Institut Teknologi Bandung, and Rock Mechanic and Mining Equipment Laboratory of Institut Teknologi Bandung for all support and discussion during conducting this research.

\section{References}

[1] Hartman, H.L. (1987) Introductory Mining Engineering. Wiley-Interscience, New York.

[2] Bell, F.G., Stacey, T.R. and Genske, D.D. (2000) Mining Subsidence and Its Effect on the Environment: Some Differing Examples. Environmental Geology, 40, 135-152. http://dx.doi.org/10.1007/s002540000140

[3] Marinos, P. and Hoek, E. (2000) GSI: A Geologically Friendly Tool for Rock Mass Strength Estimation. Proceedings of the International Conference on Geotechnical and Geological Engineering, Lancaster, 1422-1446.

[4] Hoek, E. and Brown, E.T. (1988) The Hoek-Brown Failure Criterion-A 1988 Update. Proceedings of the 15th Canadian Rock Mechanics Symposium, Civil Engineering Department, University of Toronto, Toronto, 31-38.

[5] Hoek, E. (1990) Estimating Mohr-Coulomb Friction and Cohesion Values from the Hoek-Brown Failure Criterion. International Journal of Rock Mechanics and Mining Science \& Geomechanics Abstracts, 27, 227-229. http://dx.doi.org/10.1016/0148-9062(90)94333-O

[6] Hoek, E. and Diederichs, M.S. (2006) Empirical Estimation of Rock Mass Modulus. International Journal of Rock Mechanics and Mining Sciences, 43, 203-215. http://dx.doi.org/10.1016/j.ijrmms.2005.06.005

[7] Hoek, E. and Wood, D.F. (1987) Support in Underground Hard Rock Mines. Bulletin Canadian Institute of Mining, Metallurgy and Petroleum, 35, 1-6.

[8] Hoek, E., Kaiser, P.K. and Bawden W.F. (2000) Support of Underground Excavation in Hard Rock. A.A. Balkema, Rotterdam. http://dx.doi.org/10.1201/b16978 